\title{
Clostridium difficile - a spectrum of virulence and analysis of putative virulence determinants in the hamster model of antibiotic-associated colitis
}

\author{
S. P. BORRIELLO, J. M. KETLEY,† T. J. MITCHELL,† F. E. BARCLAY, \\ A. R. WELCH, A. B. PRICE* and J. STEPHEN†
}

Division of Communicable Diseases and "Department of Histopathology, Clinical Reseach Centre, Watford Road, Harrow, Middlesex HA1 3UJ, and +Department of Microbiology, University of Birmingham, Birmingham B15 2TT

\begin{abstract}
Summary. Each of nine different toxigenic strains of Clostridium difficile was administered orally to groups of hamsters pre-treated with clindamycin and housed individually in sterile isolator boxes. Faecal pellets and caecal contents from well, diarrhoeic, moribund and freshly dead animals were analysed for $C$. difficile and toxins A (enterotoxin) and B (cytotoxin), and tissue obtained when animals were killed was examined histologically. Not all strains were equally virulent in this model. Four strains of $C$. difficile killed all animals within $48 \mathrm{~h}$ and are designated as highly virulent for hamsters. These strains were clinical isolates from three cases of disease in man and one case in a hamster. Five strains caused death of some animals but only after 5 and up to 13 days and are designated as less virulent for hamsters. These strains were isolated from asymptomatic infants (2) and household pets (2), and from the environment (1). The surviving test hamsters were killed after 14 days and, in most cases, were colonised by $C$. difficile, though levels of toxins A and B in caecal contents were low. None of the cultures used for challenge was capsulate or hydrophobic. There was no correlation between virulence and production of toxins A and $B$ in vitro in tryptic-nitrate broth. With two strains examined, there was a correlation between virulence and toxin A (but not toxin B) production in caecal emulsions derived from clindamycin pre-treated hamsters. Caecal contents from the majority of moribund and freshly dead animals had quantities of toxin A sufficient to cause disease or death if given orogastrically. Toxin B was not produced in a fixed ratio with toxin $\mathrm{A}$. The data support the view that high virulence of $C$. difficile is determined by efficient disease-inducing colonisation of the gut and the ability to generate, rapidly, high levels of toxin A in vivo.
\end{abstract}

\section{Introduction}

The virulence of a pathogen is determined not only by its genetic potential to make virulence determinants, but also by the degree to which such potential is expressed in vivo in ecologically significant conditions which are often complex and changing. The causation of disease is determined by the interaction of virulence determinants and host target tissues. These axioms must apply to Clostridium difficile for which important questions remain unanswered. In particular, is there a correlation between toxin production and the spectrum of gastro-intestinal disease that ranges

Received 12 May 1986; revised version accepted 16 Sep. 1986. from mild diarrhoea to pseudomembranous colitis (Borriello and Larson, 1981; Brettle et al., 1982; Burdon, 1984)? Furthermore, it is difficult to explain the apparent paradox of the carriage of toxin-producing $C$. difficile by asymptomatic infants if toxin A or B, or both, are important determinants of disease (Borriello, 1979; Libby et al., 1983; Lyerly and Wilkins, 1984).

In this paper we describe attempts to correlate degrees of pathological change observed in hamsters with the presence of $C$. difficile in faecal and caecal contents, bacterial surface hydrophobicity, capsule formation, and production of toxins $\mathrm{A}$ and $B$ in vitro and in vivo. We have used a range of toxigenic strains of $C$. difficile in the Syrian hamster model which has been used extensively in the 
elucidation of the aetiology of antibiotic-associated diarrhoea and colitis (Bartlett et al., 1978a; Chang et al., 1978) and has yielded important information on some aspects of pathogenicity (Price et al., 1979; Borriello and Barclay, 1985a), epidemiology (Larson et al., 1980) and treatment (Bartlett et al., 1977, $1978 b$; Browne et al., 1977) of $C$. difficile-induced disease.

\section{Materials and methods}

\section{Organisms: strains and cultural conditions}

Source and identification of $C$. difficile. All strains of $C$. difficile were isolated at the Clinical Research Centre from various sources (table I). The strains used in our animal studies and those isolated during the experiments were identified by their ability to grow on selective agar medium (Willey and Bartlett, 1979; Borriello and Honour, 1981), characteristic fluorescence of colonies under longwave ultraviolet light (George et al., 1979), colony and cell morphology on non-selective medium (Borriello and Honour, 1981), characteristic volatile fatty-acid products of metabolism (Holdeman et al., 1977) after growth in Chopped-Meat Carbohydrate Broth (CMC) (Southern Group Laboratories, Hither Green, London), and carbohydrate-fermentation reaction profiles (Holdeman et al., 1977).

Incubation conditions. Anaerobic incubation was at $37^{\circ} \mathrm{C}$ in an atmosphere of $\mathrm{CO}_{2} 10 \%, \mathrm{H}_{2} 10 \%$, and $\mathrm{N}_{2}$ $80 \%$ in an anaerobic incubator housed in an anaerobic cabinet (Forma Scientific, Marletta, OH, USA).

Preparation of inocula for animal experiments. Startercultures of $C$. difficile were prepared by inoculating 0.5 $\mathrm{ml}$ volumes of Robertson's cooked meat cultures into $10 \mathrm{ml}$ of pre-reduced Brain Heart Infusion Broth (Difco) containing L-cysteine $\mathrm{HCl} 0.05 \% \mathrm{w} / \mathrm{v}$ and sodium formaldehyde sulphoxylate $0.03 \% \mathrm{w} / \mathrm{v}$ as reducing agents (BHI broth). Cultures were incubated anaerobically for
$18 \mathrm{~h}$ and $5 \mathrm{ml}$ of a starter culture was inoculated into $100 \mathrm{ml}$ of BHI broth, incubated for $18 \mathrm{~h}$, and then centrifuged at $4500 \mathrm{rpm}$ at $4^{\circ} \mathrm{C}$ for $15 \mathrm{~min}$; the pellet was resuspended and centrifuged twice in 100-ml vols of fresh BHI broth. The final pellet was suspended in $10 \mathrm{ml}$ of fresh BHI broth and this provided the inoculum for the animal experiments. Suspensions of all strains of $C$. difficile invariably contained $10^{8} \mathrm{cfu} / \mathrm{ml}$.

Isolation of C. difficile from animals. Faecal pellets and caecal contents were screened for the presence of $C$. difficile by direct application of a small sample of undiluted material with a wire loop on to a selective medium (Borriello and Honour, 1981) incorporating sodium taurocholate $0.01 \% \mathrm{w} / \mathrm{v}$ (Raibaud et al., 1980; Wilson et al., 1982). Viable counts were determined by the method of Miles et al. (1938); 10- $\mu$ l volumes of eight serial ten-fold dilutions of faecal pellets or caecal contents in BHI broth were seeded on to the selective agar described above. All cultures were incubated anaerobically for $48 \mathrm{~h}$ at $37^{\circ} \mathrm{C}$. In all cases at least three isolates of $C$. difficile from each animal were screened for production of toxin B in vitro, to confirm that any observed lower virulence was not due to chance colonisation of the animal with protective non-toxigenic strains (Borriello and Barclay, 1985a).

\section{Organisms: hydrophobicity and capsules}

Hydrophobicity testing. Surface properties of strains of C. difficile were tested by the method described by Ljungh and Wadstrom (1982), based on precipitation of cells by ammonium sulphate (Lindahl et al., 1981). The method was modified in that cells were taken with a wire loop from 48-h colonies of $C$. difficile growing on Columbia blood-agar plates (Difco) and directly applied to $20-\mu$ l drops of ammonium sulphate solutions $(0-4 \mathrm{M})$ placed on a glass slide.

Detection of capsule. Strains were grown on Columbia blood agar incubated anaerobically. Colonies were screened after growth for 24,48 and $72 \mathrm{~h}$ for cells

Table I. Sources of $C$. difficile strains

\begin{tabular}{|c|c|c|}
\hline Strain & Source & Reference \\
\hline B-1 & $\begin{array}{l}\text { Faeces of patient with } \\
\text { pseudomembranous colitis }\end{array}$ & Borriello and Barclay, $1985 a$ \\
\hline P-1 & $\begin{array}{l}\text { Faeces of patient with } \\
\text { pseudomembranous colitis }\end{array}$ & Borriello and Barclay, $1985 a$ \\
\hline PT & $\begin{array}{l}\text { Faeces of patient with recurrent } \\
\text { antibiotic-associated diarrhoea }\end{array}$ & $\cdots$ \\
\hline 2B & $\begin{array}{l}\text { Caecal contents of hamster with } \\
\text { ileocaecitis }\end{array}$ & Larson et al., 1982 \\
\hline Tra 5/5 & Faeces of healthy infant & Larson et al., 1982 \\
\hline MA & Faeces of healthy infant & $\cdots$ \\
\hline Bat & Ward environment of neonatal unit & Larson et al., 1982 \\
\hline SC & Faeces of cat & Borriello et al., 1983 \\
\hline DD & Faeces of duck & Borriello et al., 1983 \\
\hline
\end{tabular}


possessing capsules by the Indian ink stain (Cruickshank, 1969). A highly virulent strain (B-1) and a poorly virulent strain (Bat) were also examined by electronmicroscopy for capsular material by the method of Bayer et al. (1985).

\section{Toxin assays}

Toxin A. Cell-free filtrates of $C$. difficile grown in prereduced Tryptic Nitrate Broth (TNB) (Ketley et al., 1984) and caecal or faecal pellet emulsions were assayed by an ELISA assay (Redmond et al., 1985).

Toxin B. Caecal contents or faecal pellets were diluted 10-fold in Hanks's Balanced Salts Solution and filtered, and serial doubling dilutions were applied to monolayers of African Green Monkey kidney (VERO) cells. Cellfree filtrates derived from anaerobic cultures of $C$. difficile in TNB or CMC broth (harvested after 96 and $48 \mathrm{~h}$ respectively) were tested similarly for the presence of toxin B, except that TNB filtrates were assayed in McCoy cells. (There was no special significance in these and other slight procedural changes which merely reflected ongoing routine practices in the two collaborating laboratories.) The level of cytotoxin was defined as the last dilution causing a cytopathic effect (CPE). The specificity of the CPE was determined in neutralisation tests with a cross-reacting $C$. sordelli antitoxin (Wellcome Research Laboratories, Beckenham, Kent).

\section{Production of toxins $A$ and $B$ in vitro}

Toxin production in broth. The amounts of toxins A and $B$ produced in vitro by different strains of $C$. difficile were assessed after anaerobic incubation for $96 \mathrm{~h}$ in TNB (Ketley et al., 1984).

Growth of, and toxin production by, two strains of $C$. difficile in caecal emulsions. Growth of $C$. difficile strains B-1 and Bat in caecal emulsions derived from a hamster given an intraperitoneal (ip) injection, 5 days previously, of $0.5 \mathrm{ml}$ of a solution of clindamycin phosphate $10 \mathrm{mg} /$ $\mathrm{ml}$, was performed as described by Borriello and Barclay (1986). Briefly, caecal contents were diluted ten-fold in distilled water and $10 \mathrm{ml}$ of this dilution was seeded with $0.1 \mathrm{ml}$ of a suspension of actively growing $C$. difficile (c. $\left.10^{8} \mathrm{cfu} / \mathrm{ml}\right)$. This was performed in duplicate with material from two different hamsters. Seeded material was incubated anaerobically and, after $48 \mathrm{~h}$, viable $C$. difficile counts and levels of toxins $\mathrm{A}$ and $\mathrm{B}$ were determined. The same procedure was repeated with a caecal emulsion derived from two healthy, untreated hamsters.

\section{Experiments in vivo}

Animals. Adult Syrian hamsters (Mesocricetus auratus), supplied from the National Institute for Medical Research, were used in all experiments. Each was given a dose of $0.5 \mathrm{ml}$ of a solution of clindamycin phosphate (Dalacin C; Upjohn, Crawley, West Sussex) $10 \mathrm{mg} / \mathrm{ml}$ ip, and housed individually in isolator cages with air filters fitted in their lids (Tecniplast animal cages, Biotech Consultants Ltd, Clackmannanshire, Scotland). Cages, food, water bottles and bedding were autoclaved in sealed bags before use (Larson et al., 1980). Animals were challenged in three groups.

Group 1: Comparative virulence of strains of $C$. difficile. All animals were challenged 5 days after receiving clindamycin. Virulence was measured in terms of time to death of hamsters after oral challenge with $0.5 \mathrm{ml}$ of a $C$. difficile suspension (i.e. $5 \times 10^{7} \mathrm{cfu}$; all groups). Six hamsters received strain PT; 6 strain SC; 5 strain Bat; 5 strain P-1 ; 5 strain B-1 ; 5 strain 2B ; 4 strain DD; 4 strain MA; and 4 strain Tra 5/5. Survival of these animals was monitored and time to death recorded. Caecal contents of freshly dead or moribund animals were examined for C. difficile and toxin B.

Group 2: More detailed study of selected strains from group 1. Five days after receiving clindamycin, animals received $0.5 \mathrm{ml}$ of a suspension of $C$. difficile. Six hamsters received strain DD; five, strain B-1; five, strain Bat; and two, strain P-1. Two of the animals given strain Bat were also given strain B-1 9 days later. When possible, these animals were killed when moribund and caecal contents analysed for $C$. difficile and levels of toxins $A$ and $B$.

Group 3: Delayed challenge after clindamycin treatment. Five hamsters received $0.5 \mathrm{ml}$ of a suspension of $C$. difficile strain Bat and two received B-1, 11 days after receiving clindamycin. One hamster was given strain B-1 16 days after clindamycin. The purpose of these experiments was to assess relative virulence after longer periods between clindamycin administration and challenge. When possible, these animals were killed when moribund and the caecal contents analysed for $C$. difficile and levels of toxins A and B.

Histological examination. Material from selected killed hamsters (see tables) was prepared for histological examination as described by Price et al. (1979). Normal caecal mucosa is shown in fig. 1 .

\section{Results}

\section{Lethality to hamsters}

The effects of different strains of $C$. difficile given to hamsters 5 days after clindamycin treatment are shown in table II. Strains B-1 and P-1 were isolated from patients with pseudomembranous colitis, PT from a patient with recurrent $C$. difficile diarrhoea, and 2B from a hamster with ileocaecitis. These were classified as highly virulent because all animals except one were moribund or dead within $48 \mathrm{~h}$. The exception was one animal which received strain $\mathrm{P} 1$ and was killed after $12 \mathrm{~h}$ while still well.

In contrast, the following strains killed some of the animals at 5 days or longer. Strain Tra $5 / 5$ isolated from a healthy infant killed 2 of 4 animals between 8 and 13 days. Strain SC, isolated from a healthy cat, killed 5 of 6 animals after 5 days, and 


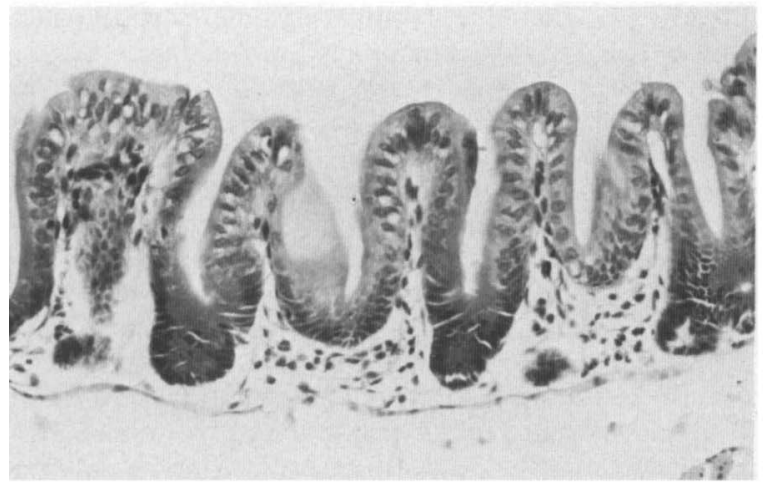

Fig. 1. Normal caecal mucosa showing regular short crypts and smooth epithelial cell surface. Haematoxylin and eosin (HE) X 275 .

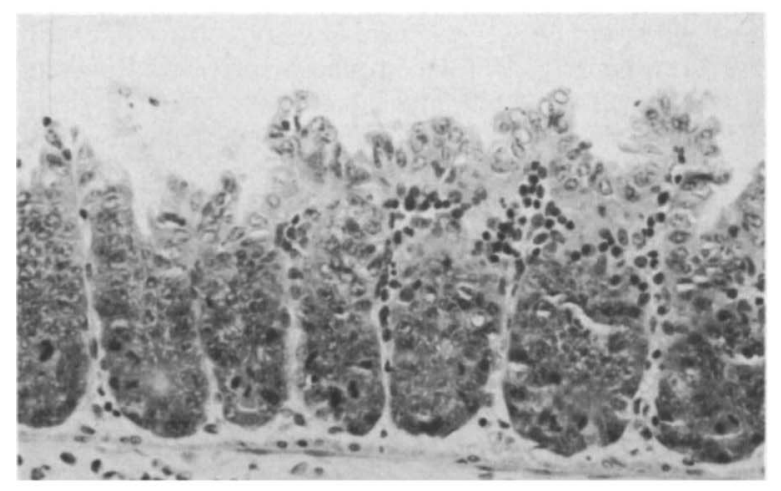

Fig. 3. Caecal mucosa from a hamster challenged with strain DD. Here the surface "tufting" gives the luminal surface an irregular outline (cf. fig. 1). The crypts are mildly hyperplastic. The areas of haemorrhage are not shown. HE, X 275.

one animal after 7 days; and strain MA, isolated from a healthy infant, caused death in 2 of 4 animals after 9 and 10 days. Strain DD isolated from a healthy duck killed 6 of 10 animals between days 6 and 12. Strain Bat isolated from the ward environment of a neonatal unit caused death in one of 10 animals. These strains were classified as less virulent.

In both groups, $C$. difficile and toxin B were detected in caecal contents of dead or moribund animals; toxin $\mathrm{A}$ was not determined in these analyses.

The results summarised in table II show that strains could be classified into highly virulent or less virulent according to whether they killed all animals within $48 \mathrm{~h}$ or some animals after 5 days; experiments were usually terminated by day 14 . What follows is an attempt to explain this differential virulence.

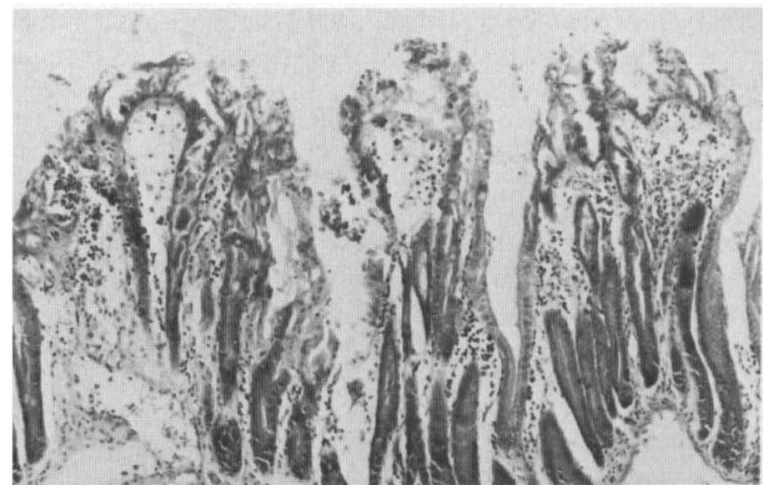

Fig. 2. Caecal mucosa from an animal challenged with strain $B 1$ demonstrating marked thickening of the mucosa, superficial inflammation and disorganisation of surface epithelium. HE, X 157.

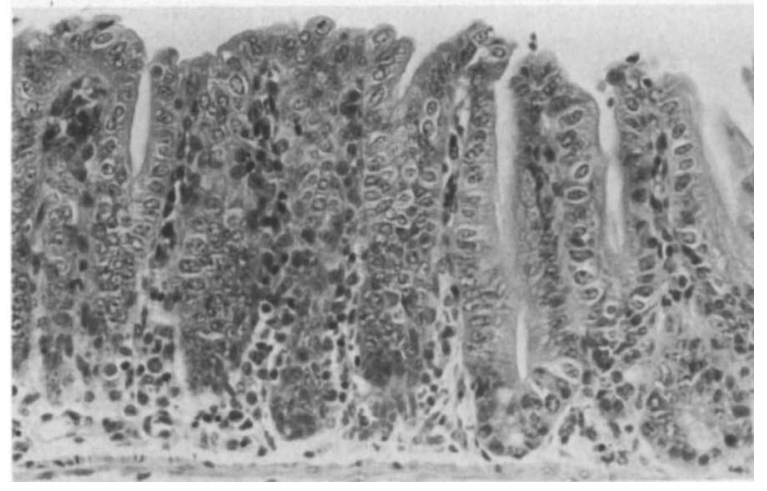

Fig. 4. Caecal mucosa from an animal challenged with strain Bat. There is elongation of the crypts and early irregularity of the surface epithelium (cf. fig. 1). HE, X 275.

\section{Hydrophobicity and capsule formation}

All strains were examined to determine whether hydrophobicity differences would explain their differing virulence, but no such difference was detected; all strains were hydrophilic - cells aggregated over the range $2-3 \mathrm{M}\left(\mathrm{NH}_{4}\right)_{2} \mathrm{SO}_{4}$. None of the strains was capsulate.

\section{Production of toxins $A$ and $B$ in vitro}

All strains were examined for toxin production in vitro in TNB media. Production of both toxins A and $B$ depended on the batch of Bactotryptose (the main constituent of TNB). The results summarised in table III show that there is no direct correlation between production of either toxin in TNB and virulence in animals; strains Tra 5/5 and MA made as much toxin B as strains B-1, P-1 and $2 B$, and the less virulent strains $M A$ and $B$ at were potent 
Table II. Virulence of different strains of $C$. difficile in hamsters pre-treated with clindamycin 5 days before challenge

\begin{tabular}{|c|c|c|c|c|c|c|c|c|c|c|c|c|c|c|c|c|c|}
\hline \multirow[b]{2}{*}{ Strain } & \multirow{2}{*}{$\begin{array}{l}\text { Number of } \\
\text { animals } \\
\text { challenged }\end{array}$} & \multicolumn{16}{|c|}{ Number of animals* moribund or dead [or killed] on indicated day after challenge } \\
\hline & & 1 & 2 & 3 & 4 & 5 & 6 & 7 & 8 & 9 & 10 & 11 & 12 & 13 & 14 & 15 & 16 \\
\hline \multicolumn{2}{|c|}{ Highly virulent } & & & & & & & & & & & & & & & & \\
\hline B-1 & 12 & 6 & 6 & & & & & & & & & & & & & & \\
\hline P-1 & 7 & $1,[1]$ & 5 & & & & & & & & & & & & & & \\
\hline PT & 6 & 1 & 5 & & & & & & & & & & & & & & \\
\hline $2 \mathrm{~B}$ & 5 & & 5 & & & & & & & & & & & & & & \\
\hline \multicolumn{18}{|c|}{ Less virulent } \\
\hline Tra $5 / 5$ & 4 & & & & & & & & 1 & & & & & 1 & [2] & & \\
\hline MA & 4 & & & & & & & & & 1 & 1 & & & [2] & & & \\
\hline $\mathrm{SC}$ & 6 & & & & & 5 & & 1 & & & & & & & & & \\
\hline DD & 10 & & & & & 2 & 1 & 2 & & [2] & & 1 & & & & & [2] \\
\hline Bat & 10 & & & & & & & & & $2 \dagger$ & & $1,[1]$ & & & [6] & & \\
\hline
\end{tabular}

* Detailed analyses of bacterial numbers and concentration of toxins A and B of selected animals are recorded in tables IV-VI.

$\dagger$ Two animals were challenged with strain B-1 on day 9 and were dead $48 \mathrm{~h}$ later.

producers of toxin A whereas only B-1 of the virulent strains made large amounts of the toxin.

An experiment was done with a presumably more relevant medium: one highly virulent strain (B-1) and one less virulent strain (Bat) were grown in caecal emulsion. The objectives were to confirm that strain Bat could grow as well as strain B-1 in the caecal contents derived from a hamster 5 days after receiving clindamycin, and to measure toxin

Table III. Extracellular levels of toxins A and B in culture supernates of strains of $C$. difficile grown in vitro in TNB

\begin{tabular}{|c|c|c|c|c|c|c|}
\hline \multirow[b]{2}{*}{ Strain } & \multicolumn{3}{|c|}{$\begin{array}{c}\text { Toxin A } \\
\text { ( } \mathrm{ng} / \mathrm{ml}) \\
\text { in medium } \\
\text { batch* }\end{array}$} & \multicolumn{3}{|c|}{$\begin{array}{c}\text { Toxin B } \\
\text { titre } \\
\text { in medium } \\
\text { batch* }\end{array}$} \\
\hline & 1 & 2 & 3 & 1 & 2 & 3 \\
\hline \multicolumn{7}{|c|}{ Highly virulent } \\
\hline B-1 & 300 & 195 & 5600 & 512 & 4096 & 4096 \\
\hline P-1 & 64 & 35 & $\ldots \dagger$ & 64 & 4096 & $\ldots$ \\
\hline PT & $<5 f$ & $<5$ & 290 & 2 & 32 & 256 \\
\hline $2 B$ & 58 & 52 & $\ldots$ & 32 & 4096 & $\ldots$ \\
\hline \multicolumn{7}{|l|}{ Less virulent } \\
\hline TRA $5 / 5$ & 22 & 27 & $\ldots$ & 32 & 4096 & \\
\hline MA & 160 & 34 & 2340 & 256 & 4096 & 4096 \\
\hline Bat & NG§ & NG & 960 & NG & NG & 1024 \\
\hline $\mathrm{SC}$ & 68 & 8 & 16 & 32 & 64 & 32 \\
\hline DD & $<5$ & $<5$ & 68 & 2 & 32 & 128 \\
\hline
\end{tabular}

\footnotetext{
* 1, 2 and 3 were separate batches of Bactotryptose used to make TNB on separate days.

$\dagger \ldots=$ Not done.

$\$$ Below the level of detection $(5 \mathrm{ng} / \mathrm{ml})$.

$\S \mathrm{NG}=$ Strain did not grow.
}

production. In both cases the strains failed to grow in pooled caecal emulsion prepared from the caecal contents of two healthy untreated hamsters but grew in emulsions derived from clindamycin pretreated hamsters. This was in keeping with earlier findings on the growth of $C$. difficile in caecal emulsions (Borriello and Barclay, 1985b, 1986). Both strains grew equally well, increasing their numbers five-fold. However, strain Bat produced an eight-fold increase in levels of toxin B (1 in 512 to 1 in 4096 ) over $48 \mathrm{~h}$; no detectable toxin $A$ was produced. In contrast, strain B-1 yielded an 85 -fold increase ( 1 in 1024 to 1 in 87381 ) in toxin B over $48 \mathrm{~h}$ and produced $79 \mathrm{ng}$ of toxin $\mathrm{A} / \mathrm{ml}$. On the basis of these findings, selected strains were chosen for more detailed analyses of faecal and caecal contents and, in particular, for levels of toxin A from infected animals that had become moribund or were freshly dead.

\section{Production of toxins $A$ and $B$ in vivo}

Highly virulent strains. The standard regimen of challenging animals 5 days after clindamycin treatment was used. Results are summarised in tables IV-VI.

Five animals challenged with strain B-1 (table IV) became moribund by $24 \mathrm{~h}$ and were killed. $C$. difficile was isolated from all animals and the highest recorded concentrations of toxin $A$ that we have ever detected for any medium were obtained from the caecal contents. High levels of toxin B were also detected but not in a fixed ratio with toxin A. Histological examination of the caeca of animals 
Table IV. Presence of $C$. difficile and toxins A and B in the caecal contents of moribund hamsters challenged, 5 days after clindamycin pre-treatment, with highly virulent strains B-1 and P-1

\begin{tabular}{ccccc}
\hline Animal & Day* & $\begin{array}{c}\text { Toxin A } \\
\mu \mathrm{g} / \mathrm{g} \dagger\end{array}$ & $\begin{array}{c}\text { Toxin B } \\
\text { titre }\end{array}$ & $\begin{array}{c}\text { Presence of } \\
\text { C. difficile }\end{array}$ \\
\hline Strain B-1 & & & & \\
A & 1 & 40 & 51200 & + \\
B & 1 & 21 & 6400 & + \\
C & 1 & 12 & 3200 & + \\
D $\ddagger$ & 1 & 38 & $>10^{6}$ & + \\
E $\ddagger$ & 1 & 82 & $>10^{6}$ & + \\
Strain P-1 & & & & \\
A & $12 \mathrm{~h} \S$ & $0 \cdot 1$ & 320 & + \\
B & 1 & $2 \cdot 4$ & 3200 & + \\
\hline
\end{tabular}

* Number of days post-challenge when hamster was found moribund and caecal contents removed.

$\dagger$ Toxin A concentration $(\mu \mathrm{g})$ per $\mathrm{g}$ wet weight of caecal material. ¥ Caeca taken for histological examination.

$\S$ Animal killed when well at $12 \mathrm{~h}$.

$\mathrm{D}$ and $\mathrm{E}$ showed changes indicative of antibioticassociated caecitis (Price et al., 1979). The crypts were elongated and their luminal halves infiltrated by polymorphs. The surface was irregular being thrown up into tufts of disorganised epithelial cells (fig. 2). In one animal there was prominent capillary congestion and early haemorrhage corresponding to macroscopic pinpoint petechial haemorrhages.

Two animals were challenged with strain $\mathrm{P}-1$ (table IV). One was killed at $12 \mathrm{~h}$ while still well and was already colonised by $C$. difficile. The other, killed when moribund at $24 \mathrm{~h}$, had a lower concentration of toxin A than observed in strain B-1 but a concentration of toxin $B$ equal to the lowest recorded for strain B-1.

Less virulent strains (i) Strain DD (table V). Six animals received strain DD. At day one, $C$. difficile was not recovered from faecal pellets from animals C-F. At day 2, animal A was killed; $C$. difficile and its toxins were not detected in the caecal contents. With animal B, organisms and toxins $A$ and $B$ were not detected in pellets obtained on days 13 and 14 or in caecal contents obtained when the animal was killed on day 16. Animals C-F became moribund (and were killed) or dead on the days indicated in table V. In all but animal C, the levels of toxin A and (where determined) toxin B were high.

Histological examination of the caecum and small bowel of animals D and E killed when moribund showed that in animal $D$ there was considerable mucosal haemorrhage in the caecum but the terminal ileum was essentially normal, and in animal $E$ there was also severe haemorrhage in the caecum. The caecal surface was focally irregular

Table V. Presence of $C$. difficile and toxins $A$ and $B$ in faeces and caecal contents of hamsters challenged, 5 days after clindamycin pre-treatment, with the less virulent strain DD

\begin{tabular}{|c|c|c|c|c|c|}
\hline Animal & Day* & $\begin{array}{c}\text { Material and state of } \\
\text { animal } \dagger\end{array}$ & $\underset{\mu \mathrm{g} / \mathrm{g}}{\operatorname{Toxin} \mathrm{A}}$ & $\begin{array}{c}\text { Toxin B } \\
\text { titre }\end{array}$ & $\begin{array}{l}\text { Presence of } \\
\text { C. difficile }\end{array}$ \\
\hline A & 2 & $\mathrm{CC} \ddagger$ (well) & $<5 \S$ & $<10 \S$ & - \\
\hline B & $\begin{array}{l}13 \\
14 \\
16\end{array}$ & $\begin{array}{l}\mathrm{F} \| \\
\mathrm{F} \\
\mathrm{CC} \text { (well) }\end{array}$ & $\begin{array}{l}<5 \\
<5 \\
<5\end{array}$ & $\begin{array}{l}<10 \\
<10 \\
<10\end{array}$ & 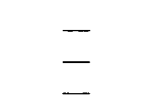 \\
\hline $\mathrm{C}$ & $\begin{array}{r}1 \\
6 \\
9\end{array}$ & $\begin{array}{l}\mathbf{F} \\
\mathbf{F} \text { (wet tail) }\end{array}$ & $\begin{array}{l}\cdots \\
<5 \\
0.01\end{array}$ & $\begin{array}{c}\ldots \\
\ldots \\
1280 \\
{ }_{* * *}\end{array}$ & $\begin{array}{c}\left.-\overline{1} 10^{2} / \mathrm{g}\right) \\
+\end{array}$ \\
\hline DT & $\begin{array}{c}11 \\
1 \\
5\end{array}$ & $\begin{array}{l}\mathrm{CC} \text { (dead) } \\
\mathrm{C} \\
\mathrm{CC} \text { (moribund) }\end{array}$ & $\begin{array}{l}0.014 \\
\ldots \\
4.4\end{array}$ & $\begin{array}{c}{ }^{* *} \\
\dddot{10} \\
>10^{7}\end{array}$ & $\frac{+}{10^{8} / g}$ \\
\hline Eף & $\begin{array}{l}1 \\
5 \\
6\end{array}$ & $\begin{array}{l}F \\
F \\
C C \text { (moribund) }\end{array}$ & $\begin{array}{l}0.05 \\
3.8\end{array}$ & $\begin{array}{l}160 \\
>10^{6}\end{array}$ & $\begin{array}{c}+ \\
+ \\
7 \times 10^{7} / g\end{array}$ \\
\hline $\mathrm{F}$ & $\begin{array}{l}1 \\
5\end{array}$ & $\begin{array}{l}\mathrm{F} \\
\mathrm{CC}(\mathrm{dead})\end{array}$ & $16 \cdot 0$ & ${ }_{+* *}$ & $\overline{+}$ \\
\hline
\end{tabular}

* Number of days post-challenge when faeces or caecal contents removed from animals.

$\dagger$ Origin of material and observed state of animal.

$\ddagger \mathrm{CC}=$ Caecal contents.

$\S$ Below level of detection ( $5 \mathrm{ng} / \mathrm{ml}$ for toxin A and titre of 10 for toxin B).

$\| \mathrm{F}=$ Faecal pellet obtained directly from apparently healthy animal.

T Caeca taken for histological examination.

** Toxin B present but not titrated. 
Table VI. Presence of $C$. difficile and toxins A and B in faeces and caecal contents of hamsters challenged, 5 days after clindamycin pre-treatment, with the less virulent strain Bat

\begin{tabular}{lrlccc}
\hline Animal & Day* & $\begin{array}{c}\text { Material and state of } \\
\text { animal }\end{array}$ & $\begin{array}{c}\text { Toxin A } \\
\mu \mathrm{g} / \mathrm{g}\end{array}$ & $\begin{array}{c}\text { Toxin B } \\
\text { titre }\end{array}$ & $\begin{array}{c}\text { Presence of } \\
\text { C. difficile }\end{array}$ \\
\hline \multirow{2}{*}{ A } & 3 & F & $<5$ & 64 & + \\
& 9 & F & $<5$ & 1280 & + \\
& 11 & CC (dead) & $6 \cdot 5$ & 20480 & + \\
B & 3 & F & $<5$ & $<10$ & - \\
& 9 & F & $<5$ & $<10$ & - \\
C & 14 & CC (well) & $0 \cdot 3$ & 320 & + \\
& 3 & F ( & $<5$ & $<10$ & - \\
D & 14 & CC (well) & $0 \cdot 3$ & 320 & + \\
& 3 & F & $<5$ & $<10$ & - \\
E $†$ & 9 & F & $<5$ & 160 & + \\
& 3 & F & $<5$ & 160 & - \\
F & 9 & F & $<5$ & 1280 & + \\
G, H, I, J & 11 & CC (well) & $\ldots$ & + & + \\
& 14 & CC (well) & $\ldots$ & + & + \\
\hline
\end{tabular}

* Number of days after challenge when faeces or caecal contents were obtained from animal. $\dagger$ Animals D and E were well and challenged with strain B-1 on day 9. Both animals died within $48 \mathrm{~h}$.

with heaping up of cells to produce tufts. Crypts were slightly elongated and this was accompanied by a mild inflammatory cell response in some areas (fig. 3). The small bowel of this animal showed some epithelial irregularity at the tips of the villi.

(ii) Strain Bat (table VI). Five animals received Strain Bat. Animal A died on day 11 with high levels of toxins A and B in caecal contents. The others remained well and were not successfully colonised (as judged by presence of $C$. difficile in faecal pellets) by day 3. Animals $D$ and $E$, which had become colonised by day 9 , were then challenged with virulent strain B-1; they died 2 days later. This confirmed that these animals were still susceptible to disease and died as if they had been exposed to strain B-1 alone.

\section{Effects of clindamycin or its metabolites}

Strains Bat and B-1 were differentially resistant to clindamycin in vitro, with MIC's of 3 and $12.5 \mathrm{mg} / \mathrm{L}$ respectively. It was considered possible that their susceptibilities to residual clindamycin, or its metabolites produced in vivo, might be greater and that 5 days after receiving clindamycin there could be sufficient levels of these compounds to inhibit successful colonisation with strain Bat but not strain B-1. Table VII shows that the time to death 11 or 16 days after clindamycin treatment for animals challenged with strain B-1 was not changed.
Strain Bat, however, caused death in one animal and severe disease (animal moribund) in another after 8 days and induced wet-tail in two animals after 9 days; one animal remained well. This pattern contrasts with death in one of 10 animals by day 11 when challenged 5 days after clindamycin (table VI). These findings still place strain Bat firmly in the less virulent group as determined by challenge 5 days after clindamycin (table II). In 3 of 4 animals (B, C and D, table VII) that became ill or died, the levels of toxin $A$ (and to a less extent toxin B) and the numbers of organisms in caecal contents were similar to those found in other animals that were moribund or dead in previous experiments.

Histological examination of caeca from two animals with wet tail (C and D; table VII) demonstrated thickened mucosa due to elongation of the caecal pits. However there was no haemorrhage or necrosis. There was some irregularity of the surface and an increase in inflammatory cells (fig. 4).

\section{Discussion}

This work clearly demonstrates that orogastric challenge of hamsters, pre-treated 5 days previously with clindamycin, differentiates toxigenic $C$. difficile strains into two categories-those that cause death in all hamsters within 2 days of infection 
Table VII. Presence of $C$. difficile and toxins A and B in faeces and caecal contents of hamsters challenged, 11 or 16 days after clindamycin pre-treatment, with strains Bat and B-1

\begin{tabular}{|c|c|c|c|c|c|c|c|}
\hline Strain & Animal & $\begin{array}{c}\text { Day } \\
\text { challenged } \\
\text { after } \\
\text { clindamycin }\end{array}$ & Day* & $\begin{array}{l}\text { Material and state } \\
\text { of animal }\end{array}$ & $\underset{\mu \mathrm{g} / \mathrm{g}}{\text { Toxin A }}$ & $\begin{array}{c}\text { Toxin B } \\
\text { titre }\end{array}$ & $\begin{array}{l}\text { Presence of } \\
\text { C. difficile }\end{array}$ \\
\hline \multirow[t]{13}{*}{ Bat } & A & 11 & 2 & $\begin{array}{l}F \\
F\end{array}$ & $<5$ & 80 & + \\
\hline & & & 8 & $\mathrm{CC}$ (moribund) & $1 \cdot 2$ & 1280 & $\begin{array}{l}+ \\
+\end{array}$ \\
\hline & B & 11 & 2 & $\mathrm{~F}$ & $<5$ & 40 & + \\
\hline & & & 7 & $F$ & & & + \\
\hline & & & 8 & CC (dead) & $4 \cdot 62$ & 5120 & + \\
\hline & $\mathrm{C} \dagger$ & 11 & 2 & $F$ & $<5$ & 640 & + \\
\hline & & & 9 & $\mathrm{CC}$ (wet tail) & $3 \cdot 1$ & 1280 & $10^{9} / \mathrm{g}$ \\
\hline & $\mathrm{D} \dagger$ & 11 & 2 & F & 0.5 & 320 & + \\
\hline & & & 7 & F & & & \\
\hline & & & 9 & $\mathrm{CC}$ (wet tail) & 3.9 & 20560 & $>10^{7} / \mathrm{g}$ \\
\hline & & & 2 & $\mathbf{F}$ & $\cdots$ & $\cdots$ & + \\
\hline & & & 7 & & & & \\
\hline & E & 11 & 9 & CC (well) & $<5$ & 64 & $10^{8} / \mathrm{g}$ \\
\hline \multirow[t]{3}{*}{ B-1 } & F & 11 & 2 & CC (dead) & $\ldots$ & + & + \\
\hline & $\mathrm{G}$ & 11 & 2 & CC (dead) & $\ldots$ & + & + \\
\hline & $\mathrm{H}$ & 16 & 2 & CC (dead) & $\ldots$ & + & + \\
\hline
\end{tabular}

* Number of days after challenge when faeces or caecal contents were obtained from animal.

† Caeca taken for histological examination.

(designated highly virulent) and those that kill some hamsters 5 days or more after infection (designated less virulent). A third group, not considered here, comprises those non-toxigenic strains that do not kill hamsters; these would be designated avirulent (Borriello and Barclay, 1985a).

Some of the work described in this paper was undertaken in an attempt to explain this apparent spectrum of virulence. At the outset, toxin A was clearly a putative determinant of pathogenicity in C. difficile-induced disease in hamsters (Lyerley $e t$ al., 1985) and, by extrapolation, in man. No evidence was found to correlate capsule or hydrophobic bacterial surfaces with virulence. However, the studies have revealed other important aspects of pathogenicity that may shed light on the progression of events during infection.

$C$. difficile does not readily colonise the normal healthy adult gut but requires the alteration of normal faecal flora by antimicrobial therapy. The work described here shows that virulence is in part determined by the potential of a strain to colonise the gut of a clindamycin pre-treated hamster. Two lines of evidence support the concept that for less virulent strains there is a period of inefficient colonisation. First, all animals received the same size of inoculum $\left(5 \times 10^{7} \mathrm{cfu}\right.$ orogastrically), yet some animals challenged with strains DD and Bat did not show detectable levels of $C$. difficile in faecal pellets 2-3 days after challenge. Furthermore, in 2 of 10 asymptomatic hamsters that received less virulent strains (tables V-VII), C. difficile could not be found after 2 and 16 days in caecal contents killed, although it was found in the other 8 . In contrast, hamsters challenged with highly virulent strains were colonised and dead by $48 \mathrm{~h}$. Second, hamsters colonised with the less virulent strain Bat and rechallenged with the highly virulent strain B-1, were dead within $48 \mathrm{~h}$. This indicates that strain Bat was not protectively colonising the hamster, in contrast to non-toxigenic, avirulent strains of $C$. difficile which have been found to be protective (Borriello et al., 1983; Wilson and Sheagren, 1983; Borriello and Barclay, 1985a).

The reasons for failure to colonise efficiently may be numerous and complex. These studies give no clear indication. The explanation cannot lie wholly in the differing susceptibilities of strains to clindamycin or its metabolites in vivo. Strains B-1 and Bat, representing the highly virulent and less virulent groups respectively, grew equally well in vitro in caecal emulsions prepared from animals that had received clindamycin 5 days previously. Although delaying the challenge to hamsters by 
strain Bat to 11 instead of 5 days after treatment with clindamycin resulted in more animals showing symptoms or dying, the pattern of virulence did not change to one typical of highly virulent strains, i.e., death of all animals within $48 \mathrm{~h}$. Furthermore, the mean level of clindamycin and its active metabolites remaining in the caecum 5 days after receiving a single ip dose of $10 \mathrm{mg}$ (i.e., twice the dose used in these experiments) is $20 \mu \mathrm{g} / \mathrm{g}$ of caecal content (range $15-30 \mu \mathrm{g} / \mathrm{g}$ ) as determined by the Staphylococcus aureus (Oxford strain) biossay (Griffin and McDougall, personal communication). These estimated levels are well below the MIC for either strain B-1 or Bat.

One possible explanation for the observed differences to colonise efficiently may be differences in the ability to associate with the gut mucosa. It has been demonstrated recently that strain B-1 associates with the gut mucosa to a greater degree than strain Bat within $24 \mathrm{~h}$ of challenge in hamsters that had received $5 \mathrm{mg}$ of clindamycin ip 20 days previously (Borriello and Welch, unpublished observations). These differences were most pronounced in the small bowel. Nevertheless, it remains possible that some of the differences between strains of $C$. difficile reflect differing reactions to sub-inhibitory levels of clindamycin.

Colonisation per se is not the only step necessary for $C$. difficile to cause disease. The present work shows that the production of toxin $A$ in vivo is also important. Several strains of different virulence in the hamster model were used to study possible correlations between levels of toxin production and virulence. Less virulent strains did produce biologically active toxins in vitro as shown by rabbit ileal loop tests and mouse lethality tests (data not shown). Production in vitro of toxins A and B was variable (table III). There was no correlation between production of toxins $\mathrm{A}$ and $\mathrm{B}$ in vitro in broth and virulence for hamsters. However, there was a correlation between the amount of toxin A produced in vitro in clindamycin-treated hamster caecal contents for the two strains examined. More important, the evidence supports the view that toxin $\mathrm{A}$, or rather the rapid production of toxin $\mathrm{A}$, in vivo plays an important role in the causation of disease and death.

In all cases the caecal contents of symptomatic animals or of those freshly dead contained toxins A and B. The levels of toxin A were high, and predictably lethal: Lyerly et al. (1985) showed that $16 \mu \mathrm{g}$ of toxin A will cause disease (intestinal damage and diarrhoea) and $32 \mu \mathrm{g}$ of toxin A will cause death within $72 \mathrm{~h}$ when given intragastrically to a $200-\mathrm{g}$ hamster. Based on the observation that a 200-g hamster challenged with $C$. difficile 5 days after pre-treatment with clindamycin has $c .10 \mathrm{~g}$ of caecal contents (unpublished observations), it can be predicted that $3.2 \mu \mathrm{g}$ of toxin $\mathrm{A} / \mathrm{g}$ of caecal content would cause death and $1.6 \mu \mathrm{g} / \mathrm{g}$ would cause disease after $72 \mathrm{~h}$. This estimated concentration of toxin A that would cause death is well within the range of toxin A concentrations associated with dead or moribund animals infected with strain B-1 in our study (table IV). In the majority of the other animals such levels of unbound toxin were approached, and this takes no account of bound toxin. Also, Lyerly et al. (1985) administered a bolus, whereas in our experiments toxin production and release were presumably continuous and increasing at the time the animals were killed. We recognise, of course, that there is animal variation in doseresponses and that extrapolations from one series to another are vulnerable.

In the experiments described here it would not be necessary to demonstrate in absolute terms the production of a lethal dose of toxin A. At the beginning of this project the individual roles of toxins $A$ and $B$ in the production of disease were not clear. In rabbit ligated ileal loops, only toxin A was found to cause fluid accumulation and tissue damage; toxin B was inactive (Taylor et al., 1981; Lyerly et al., 1982). This has been confirmed by Mitchell et al. (1986) who also found that toxin B was inactive in rabbit colonic loops. Previous reports of the activity of toxin $B$ in the hamster gastro-intestinal tract were contradictory and the situation has apparently now been resolved. Lyerly et al. (1985) reported that very high doses of toxin B $(0.5 \mathrm{mg} / \mathrm{kg})$ given intragastrically did not cause death or intestinal pathology in hamsters, mice or rats. However, when given with sub-pathological doses of toxin A or after caecal bruising, high doses of toxin $B$ resulted in damage to the small intestine and lung and in death. These data suggest that the previously reported effects of toxin B in the hamster gastro-intestinal tract were potentiated by contamination with small amounts of toxin A or procedural damage to intestinal epithelia, or both. Thus, toxin B does not appear to play a primary but could play a secondary, additive or synergic role in causing death; the same conclusions have been drawn in studies with toxin B in rabbit ileal and colonic loops. (Mitchell et al., 1987; Ketley et al., 1987).

It was noted in this study that toxin B was present in faecal pellets of hamsters challenged with less virulent strains, several days before the appearance of both toxin $\mathrm{A}$ and symptoms. This might reflect the relatively greater sensitivity of the assay for toxin B. Alternatively, it could be argued that this 
is further evidence that toxin B does not perform a primary role. The appearance of symptoms and death in hamsters was more strongly correlated with the presence of toxin $A$ in caecal contents. Overall, these results indicate that toxin $A$ is the primary toxic determinant of tissue damage leading to diarrhoea and death caused by $C$. difficile.

It is possible that the rate of toxin production is perhaps more important than the absolute level of toxin achieved. The gut epithelium is a tissue with a high turnover in health and the rate presumably increases during disease. Cells are continuously being shed at a normal (or in disease at an accelerated) rate from villus tips and replaced by cells from the crypts. There is evidence that exposure of ileum of non-immune animals to low doses of toxin A (Mitchell et al., 1986) or of ileum from immune animals to higher doses of toxin A (Ketley et al., 1987) results in fairly rapid resealing of injured epithelia. Thus, the rate of toxin production must be more than a certain minimum such that the rate of tissue damage exceeds that of tissue repair. As the rate of toxin production increases, the balance between damage and repair will shift in favour of net damage. As tissue damage (in particular, dysfunction or removal of the transporting epithelium leading to access to vascular tissue) is a pre-requisite of toxin-A-induced diarrhoea (Mitchell et al., 1987) then it might be predicted that a low level of tissue damage would produce such a low volume of diarrhoea that other undamaged areas of the intestine would be able to resorb secreted fluid. Thus, there would be no net loss of fluid and, therefore, no clinically evident diarrhoea. The continued existence of such a balance of tissue damage and repair could explain the lack of symptoms in neonates colonised with $C$. difficile whose stools contain both toxins $\mathbf{A}$ and $\mathbf{B}$. One could speculate that $C$. difficile produces toxins at a lower, non-disease-producing rate in a gut that might also be inherently less susceptible for various reasons such as lack of toxin receptors, or increased rate of toxin inactivation. Although toxin $A$ has been detected in the stools of adults with $C$. difficileinduced disease and $C$. difficile-colonised healthy infants, accurate comparisons of the levels of stool toxin A have not been made. However, it has been reported that asymptomatic infants had levels of $c$. $250 \mathrm{ng} / \mathrm{g}$ and that an infant with antibiotic-associated colitis due to $C$. difficile had levels of $1.2 \mu \mathrm{g} / \mathrm{g}$ of stool (Libby et al., 1983).

If toxin A plays a major role in C. difficile-induced disease, the time between initiation of rapid toxin production and disease or death would be relatively short, as indicated by the pattern of rapid appear- ance of high levels of toxins A and B just before onset of morbidity or lethality with highly virulent strains in our animal studies (table IV). This would be similar to what has been observed in $C$. spiroforme-associated enterotoxaemia of rabbits; the organism can be recovered from the caecum for up to $15 \mathrm{~h}$ before the detection of iota toxin. Diarrhoea occurs soon after toxin production and the animal then dies within $8 \mathrm{~h}$ (Carman et al., 1985). In the case of disease induced in the hamster by low-virulence strains of $C$. difficile, most animals had $C$. difficile detectable in faecal pellets before the appearance of toxins. Therefore, it is possible that animals are colonised soon after challenge with low-virulence strains, but for some as yet unknown reason high rates of toxin production are not initiated for some considerable time. Therefore, the difference in virulence between these strains may be due to differences in virulence determinants associated with "efficient" colonisation, which may be related to differences in the ability to associate with the gut mucosa noted above. Alternatively, lower virulence could result from the production of lower levels of toxins per se, with morbidity and lethality being ascribed to the cumulative action of low toxin concentrations over a longer period of time. That this is unlikely is based on the considerable overlap between the ranges in caecal concentrations of toxins A and B in moribund or freshly dead hamsters challenged with strains of high or low virulence. For example, two moribund hamsters challenged with the highly virulent strains $\mathrm{P}-1$ (animal B, $2 \cdot 4 \mu \mathrm{g} / \mathrm{g}$ ) or B-1 (animal C, $12 \mu \mathrm{g} / \mathrm{g}$ ), had caecal toxin $A$ concentrations within the range found with less virulent strains $(1 \cdot 2-16 \mu \mathrm{g} / \mathrm{g}$; tables IV-VII).

Toxins A and B were definitely not co-produced in a fixed ratio in vivo. Lyerly et al. (1983) stated that toxins A and B were co-produced in a fixed ratio in vitro, but this has recently been disproved in studies with both complex and chemically defined media (Haslam et al., 1986). Such a wide range of toxin-B concentrations associated with disease or death further supports the view that toxin $A$ is probably more important than $B$ as a determinant of virulence.

The histological picture presented here is in keeping with predictions that could be based on the biological mode of action proposed by Mitchell $e t$ al. (1987) and Ketley et al. (1987) for toxin A. This histo-toxic toxin has a progressive mode of action with removal of epithelial cells followed by an attack on endothelia giving rise to gross haemorrhage and bloody luminal fluid (rabbit ileum) or a delayed tissue-localised haemorrhage and watery 
luminal fluid (rabbit colon). Histological examination of hamster caeca revealed that all symptomatic animals had the first stage of epithelial damage, but only moribund animals (and not those with only wet tail) showed the secondary more severe haemorrhagic stages of toxin A action. At this point, both toxins would be rapidly absorbed to exercise their lethal effects.

This work has demonstrated for the first time that there may be differences in virulence between toxigenic strains of $C$. difficile. These differences may help to explain the spectrum of disease

\section{REFERENCES}

Bartlett J G, Chang T-W, Gurwith M, Gorbach S L, Onderdonk A B 1978a Antibiotic-associated pseudomembranous colitis due to toxin-producing clostridia. New England Journal of Medicine 298:531-534.

Bartlett J G, Chang T-W, Onderdonk A B $1978 b$ Comparison of five regimens for treatment of experimental clindamycinassociated colitis. Journal of Infectious Diseases 138:81-86.

Bartlett J G, Onderdonk A B, Cisneros R L 1977 Clindamycinassociated colitis in hamsters: protection with vancomycin. Gastroenterology $73: 772-776$.

Bayer M E, Carlemalm E, Kellenberger E 1985 Capsule of Escherichia coli K29: Ultrastructural preservation and immunoelectron microscopy. Journal of Bacteriology 162:985-991.

Borriello S P 1979 Clostridium difficile and its toxin in the gastrointestinal tract in health and disease. Research and Clinical Forum 1 : 33-35.

Borriello S P, Barclay F E $1985 a$ Protection of hamsters against Clostridium difficile ileocaecitis by prior colonisation with non-pathogenic strains. Journal of Medical Microbiology 19:339-350.

Borriello S P, Barclay F E $1985 b$ Colonization resistance to Clostridium difficile infection. Microecology and Therapy 14:75-78.

Borriello S P, Barclay F E 1986 An in-vitro model of colonisation resistance to Clostridium difficile infection. Journal of Medical Microbiology 21 :299-309.

Borriello S P, Honour P 1981 Simplified procedure for the routine isolation of Clostridium difficile from faeces. Journal of Clinical Pathology 34: 1124-1127.

Borriello S P, Honour P, Turner T, Barclay F E 1983 Household pets as a potential reservoir for Clostridium difficile infection. Journal of Clinical Pathology 36:84-87.

Borriello S P, Larson H E 1981 Antibiotics and pseudomembranous colitis. Journal of Antimicrobial Chemotherapy 7 Suppl A:53-62.

Brettle R P, Poxton I R, Murdoch J M, Brown R, Byrne M D, Collee J G 1982 Clostridium difficile in association with sporadic diarrhoea. British Medical Journal 284:230-233.

Browne R A, Fekety R, Silva J, Boyd D I, Work C O, Abrams G D 1977 The protective effect of vancomycin on clindamycin-induced colitis in hamsters. Johns Hopkins Medical Journal 141 : 183-192.

Burdon D W 1984 Spectrum of disease. In: Borriello S P (ed) Antibiotic-associated diarrhoea and colitis. Martinus Nijhoff Publishers. The Hague, p 9.

Carman R J, Borriello S P, Waynforth H B 1985 Microbiological resulting from infection in man. The final outcome of infection will depend on several interacting factors such as the degree of colonisation resistance exerted by the remaining gut flora, the levels of antibiotic in the gut, the antibiotic sensitivities of C. difficile, and the potential virulence of the infecting organism.

JS thanks the MRC for grant support and a studentship to JK, and Pfizer Central Research and SERC for a CASE award to TM. We thank H. A. Davies for electronmicroscopy.

changes during experimental Clostridium spiroforme mediated diarrhoea (iota enterotoxaemia) of rabbits. In: Archibald $\mathrm{J}$ et al. (eds) Proceedings of the 8th ICLAS/ CALAS Symposium, Gustav Fischer Verlag, Stuttgart, p 471.

Chang T-W, Bartlett J G, Gorbach S L, Onderdonk A B 1978 Clindamycin-induced enterocolitis in hamsters as a model of pseudomembranous colitis in patients. Infection and Immunity 20:526-529.

Cruickshank R 1969 Medical Microbiology 11 th edn (revised). E and S Livingstone Ltd, Edinburgh, p 659.

George W L, Sutter V L, Citron D, Finegold S M 1979 Selective and differential medium for isolation of Clostridium difficile. Journal of Clinical Microbiology 9:214-219.

Haslam S C, Ketley J M, Mitchell T J, Stephen J, Burdon D W, Candy D C A 1987 Growth of Clostridium difficile and production of toxins A and B in complex and defined media. Journal of Medical Microbiology 21 : 293-297.

Holdeman L V, Cato E P, Moore W E C (eds) 1977 Anaerobe laboratory manual 4th edn. Virginia Polytechnic Institute and State University, Blacksburg, VA.

Ketley J M, Haslam S C, Mitchell T J, Stephen J, Candy D C A, Burdon D W 1984 Production and release of toxins A and $\mathbf{B}$ by Clostridium difficile. Journal of Medical Microbiology 18:385-391.

Ketley J M, Mitchell T J, Candy D C A, Burdon D W, Stephen J 1987 The effects of Clostridium difficile crude toxins and toxin A on ileal and colonic loops in immune and nonimmune rabbits. Journal of Medical Microbiology 24:4152.

Larson H E, Barclay F E, Honour P, Hill I D 1982 Epidemiology of Clostridium difficile in infants. Journal of Infectious Diseases. 146: 727-733.

Larson H E, Price A B, Borriello S P 1980 Epidemiology of experimental enterocecitis due to Clostridium difficile. Journal of Infectious Diseases 142:408-413.

Libby J M, Donta S T, Wilkins T D 1983 Clostridium difficile toxin A in infants. Journal of Infectious Diseases 148: 606.

Lindahl M, Faris A, Wadström T, Hjerten S 1981 A new test based on "salting out" to measure relative surface hydrophobicity of bacterial cells. Biochimica et Biophysica Acta 677:471-476.

Ljungh $\AA$, Wadström T 1982 Salt aggregation test for measuring cell surface hydrophobicity of urinary Escherichia coli. European Journal of Clinical Microbiology 1 :388-393.

Lyerly D M, Lockwood D E, Richardson S H, Wilkins T D 1982 Biological activities of toxins $A$ and $B$ of Clostridium difficile. Infection and Immunity 35: 1147-1150.

Lyerly D M, Saum K E, MacDonald D K, Wilkins T D 1985 
Effects of Clostridium difficile toxins given intragastrically to animals. Infection and Immunity 47:349-352.

Lyerly D M, Sullivan N M D, Wilkins T D 1983 Enzyme-linked immunosorbent assay for Clostridium difficile toxin A. Journal of Clinical Microbiology 17:72-78.

Lyerly D M, Wilkins T D 1984 Characteristics of the toxins. In: Borriello S P (ed) Antibiotic-associated diarrhoea and colitis. Martinus Nijhoff Publishers, The Hague, p 89.

Miles A A, Misra S S, Irwin J O 1938 The estimation of the bactericidal power of the blood. Journal of Hygiene 38 : 732749.

Mitchell T J et al. 1986 Effect of toxin A and B of Clostridium difficile on rabbit ileum and colon. Gut 27:78-85.

Mitchell T J, Ketley J M, Burdon D W, Candy D C A, Stephen J 1987 Biological mode of action of Clostridium difficile toxin A: a novel enterotoxin. Journal of Medical Microbiology 23:211-219.

Price A B, Larson H E, Crow J 1979 Morphology of experimental antibiotic-associated enterocolitis in the hamster: a model for human pseudomembranous colitis and antibioticassociated diarrhoea. Gut 20:467-475.

Raibaud P, Ducluzeau R, Dubos F, Hudault S, Bewa H, Muller M C 1980 Implantation of bacteria from the digestive tract of man and various animals into gnotobiotic mice. American Journal of Clinical Nutrition 33:2440-2447.

Redmond S C, Ketley J M, Mitchell T J, Stephen J, Burdon D W, Candy D C A 1985 Detection of Clostridium difficile enterotoxin (toxin A) by ELISA and other techniques. In: Collins $\mathbf{C ~ H}$, Grange $\mathbf{J} \mathbf{M}$ (eds) Isolation and identification of micro-organisms of medical and veterinary importance. (Society of Applied Bacteriology, Technical Series 21), Academic Press, London, pp 237-250.

Taylor N S, Thorne G M, Bartlett J G 1981 Comparison of two toxins produced by Clostridium difficile. Infection and Immunity 34: 1036-1043.

Willey S H, Bartlett J G 1979 Cultures for Clostridium difficile in stools containing a cytotoxin neutralized by Clostridium sordelli antitoxin. Journal of Clinical Microbiology 10:880884.

Wilson K H, Kennedy M J, Fekety F R 1982 Use of sodium taurocholate to enhance spore recovery on a medium selective for Clostridium difficile. Journal of Clinical Microbiology 15 : 443-446.

Wilson K H, Sheagren J N 1983 Antagonism of toxigenic Clostridium difficile by non-toxigenic C. difficile. Journal of Infectious Diseases 147: 733-736. 